\title{
Butadiene Rubber in the Petrochemical Industry
}

\author{
Abdulaziz K Bubshait \\ Saudi Aramco \\ ${ }^{*}$ Corresponding author email: aziz088@ hotmail.com \\ Received: 20 December 2021 / Revised: 27 December 2021 / Accepted: 29 December 2021 / Published: 31 December 2021
}

\begin{abstract}
The Butadiene is a raw material used in the petrochemical industry. The use of Butadiene has risen with petrochemical market growth. The Global market is forecasting a demand growth for butadiene applications, especially for rubber materials. The estimated synthetic rubber market is $\$ 19.1$ billion in 2021 and forecasted to reach $\$ 23.2$ billion in five years. The dynamic growth in butadiene applications will introduce new products used in many things from the food industry to sports and goods. Also, the rubber materials have different applications in the automotive industry, oil and gas, medical products, and plastics. Companies' strategic planning to increase the production of synthetic rubber for the global market. The demand increased as new applications were introduced to the market. The stability of oil prices will have the rubber market steady which always leads to optimal pricing. The diver for Butadiene rubber applications is to maximize production by having different kind of materials that applied for several products. The global business development indicated the ability to increases the synthetic rubber market rubber and capacities, which will enhance the chemical process techniques, new technology design, and efficiency that will maximize production and minimize product cost. Looking into the price difference between synthetic and natural rubber, many fluctuation variables were introduced in the price of each type. For example, synthetic rubber price is high, depending on crude oil, natural gasoline and naphtha prices, since those feedstocks are fed to the cracking units, as C4 is one of the cracking products. Therefore, any change in the oil prices will influence the butadiene price, which is the feed for most rubber plants. In addition, the utilities required for those plants to operate have a major impact on overall price. On the other hand, Natural rubber is an agricultural product and dependent on soil type and weather.
\end{abstract}

Keywords: Butadiene, Rubber, Petrochemical.

\section{Introduction}

The petrochemical industry is facing various revolutions and technologies innovations to improve the rubber market applications. In the middle of the 18th century, butadiene was introduced to the chemical industry to obtain a substitute for natural rubber. In the period from World War I to (and including) World War II, rubber demand increased. Countries that were involved in the arms industry required rubber to produce weapons. For example, the U.S. Government started a research and development project to develop butadiene rubber, to replace natural rubber. In addition, the Russians were the first to prepare a synthetic rubber. This technical paper will provide an overview of Butadiene rubber materials and associated applications in different areas. In additional, this paper will highlight the natural rubber and butadiene synthetic rubber processes and will highpoints the advantages for several rubbers' materials.

The rubber markets are growing for both natural rubber from plants [1], and synthetic rubber from Butadiene. The main difference between natural and synthetic rubbers the method of production. There are also different physical and chemical properties [2]. A variety of synthetic rubbers and polymers are processed from butadiene with different properties. 


\section{Synthetic Butadiene Rubber}

Synthetic butadiene rubber is a manmade polymer, synthesized from oil, and the rubber's properties can adjust to fit the final application [1]. Synthetic butadiene rubber is one of the main products after the extraction of butadiene from the $\mathrm{C} 4$ feeder to a synthetic rubber plant. A variety of synthetic rubbers and polymers are processed from butadiene with different properties, such as, Polybutadiene Rubber (BR), which has good elasticity and flexible at temperature. Isoprene Rubber (IR) has outstanding strength and excellent compression that makes IR the preferred material for many applications. Acrylonitrile Butadiene Rubber (NBR) is oil and fuel resistant, and resistant to abrasion [3]. Styrene Butadiene Rubber (SBR) has lower elasticity and excellent electrical insulation properties.

\subsection{Polybutadiene Rubber (BR)}

The most common type of rubber is Polybutadiene which is high wear excellent elastic and it's known as highly resistance of low temperature (Figure 1). The main application for PBR is tire industry [3].

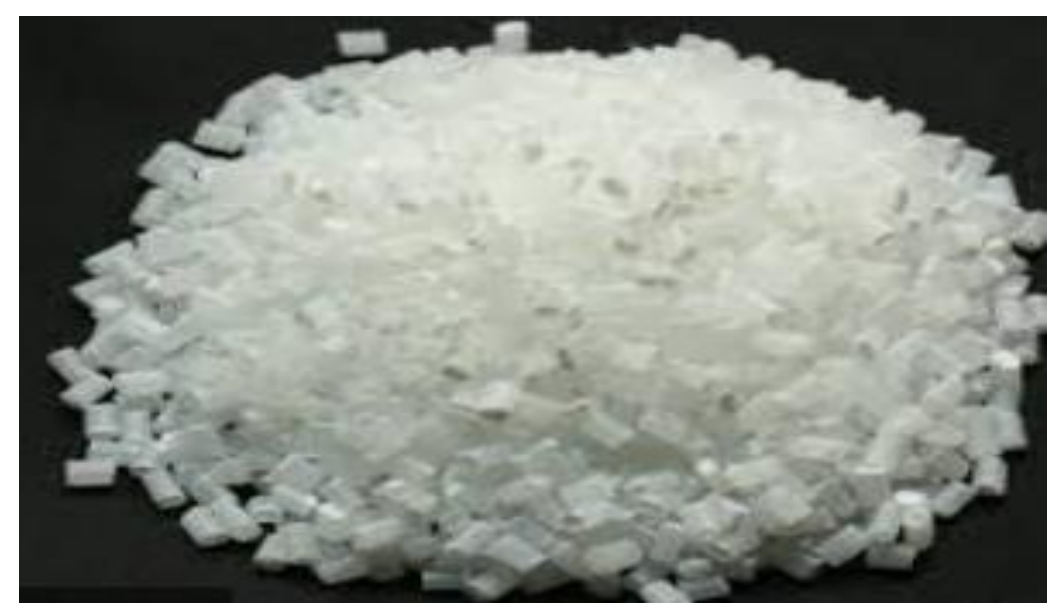

Figure 1: Polybutadiene Rubber materials after plant production

\subsection{Acrylonitrile Butadiene Rubber (NBR)}

NBR is one of the butadiene rubbers used in piping and seal applications. Due to the chemical and physical properties which are heat distortion and resistant to scratches (Figure 2) [3].

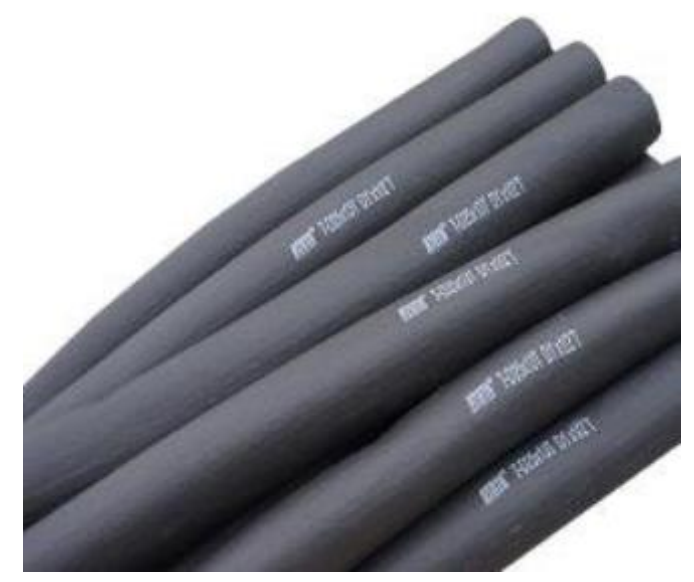

Figure 2: NBR piping material used in oil Industry

\subsection{Isoprene Rubber (IR)}

IR are known as high strength and good resistance which make this material more needed in many applications (Figure 3) [3]. 
Abdulaziz K Bubshait, Int. Ann. Sci.; Vol. 11, Issue 1, pp: 22-26, 2021

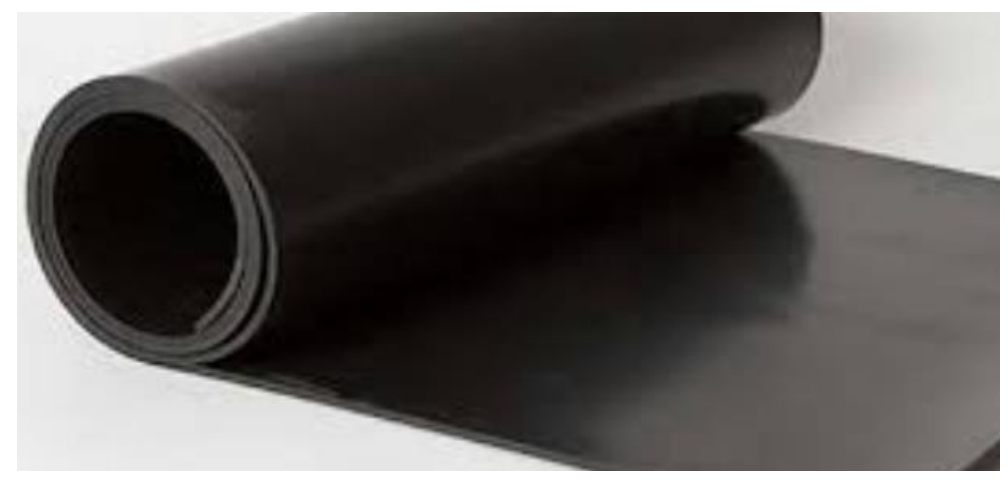

Figure 3: IR Rubber used in Tire Industry and very likely to Natural Rubber

\subsection{Synthetic Butadiene Rubber Process}

The synthetic rubber process follows specific steps that depend on the type of rubber. The process starts with mixing naphtha with natural gases produced from the cracking process, then adding chemical agents to turn individual polymers into polymer chains. Then the vulcanization process improves the elasticity and strength by heating the rubber with sulfur. Finally, the rubber is molded into desired shape before completing the rubber production process.

\subsection{Synthetic Butadiene Rubber technology}

To build and operate C4 technology plants, companies procure technologies to achieve the product specifications required. Specific property materials and equipment, such as catalysts and chemical solvents, govern those technologies. Licensors and technology providers ensure valid products that meet the international requirements for their licensees. For example, to produce butadiene, the project shall start with signing two-types of agreements, Engineering and Technology Transfer Agreements. The Engineering Agreement allows the client to receive the engineering drawings and Basic Engineering Package. This includes all engineering requirements to start the feasibility study and complete the project proposal before commencing the execution phase of the project. The Technology Transfer Agreement supports the project during the startup, commissioning, pre-commissioning and operation to achieve the accurate yields and product specification. Each licensor competing in the market provides the minimum OPEX for the plant design. The plants deliver the maximum efficiency, stability and reliability.

\subsection{Butadiene Extraction}

Butadiene is extracted from C4 through four main processes inside the process unit. Starting with predistillation of the crude $\mathrm{C} 4$, then extractive distillation by introducing solvent components inside the vessels. Afterward a degassing process to ensure no loss of product. Finally, a re-distillation process to extract the final butadiene product. Each licensor competing in the market provides the minimum OPEX for the plant design. The plants deliver the maximum efficiency, stability and reliability [4].

\section{Natural Rubber}

The method of production is the main different between butadiene and natural rubbers [5]. There are also different physical and chemical properties. Natural rubber is a polymer found from natural plants (Figure 4). The geographical area and clone quality including the weather play major role in the production of Natural rubber. 


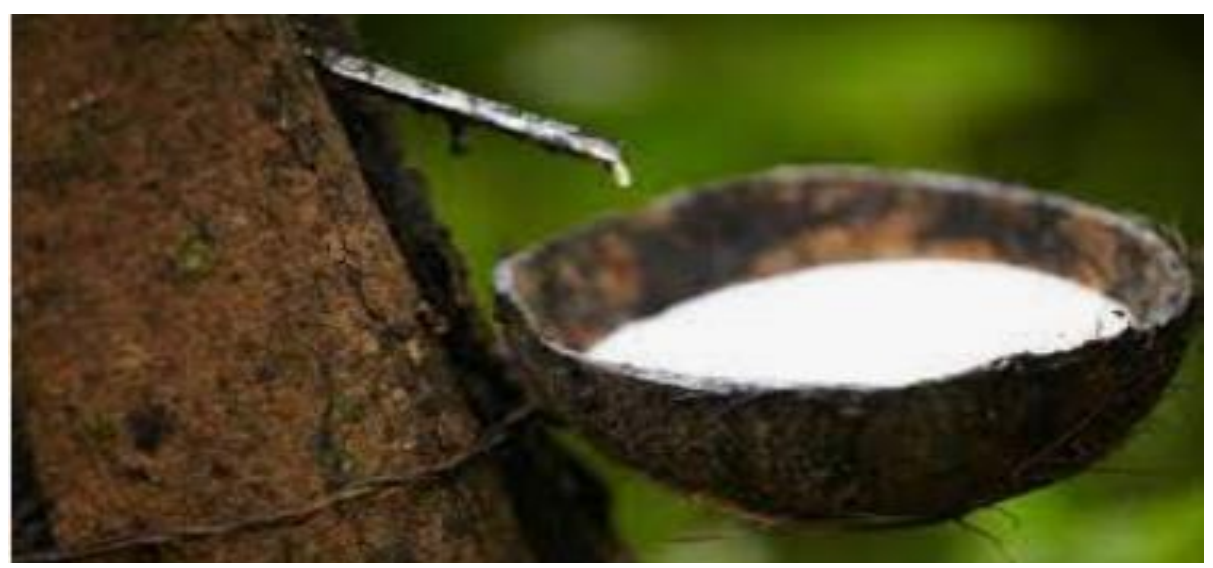

Figure 4: Natural Rubber draping from plant called Hevea brasiliensis

Natural Rubber has several resistance and dynamic performance [5]. The production of natural rubber involves four main processes. Starting with the mastication process, the elastomer needs to be brokendown, and followed by the mixing process when additives are incorporated. The third process is shaping of the viscous mass. The last step is the curing process, when the polymer molecules become interlinked and the shape is fixed.

\subsection{Natural Rubber market}

The market for natural rubber is rapidly growing and the demand volume was approximately 15.2 million metric tons in 2020 [3]. That volume is expected to grow by $5 \%$ during the next five years. The largest regional market for natural rubber is the Asia Pacific, Indonesia, and Malaysia are the major exporters. Natural Rubber grips around $40 \%$ of the world rubber market (Figure 5).

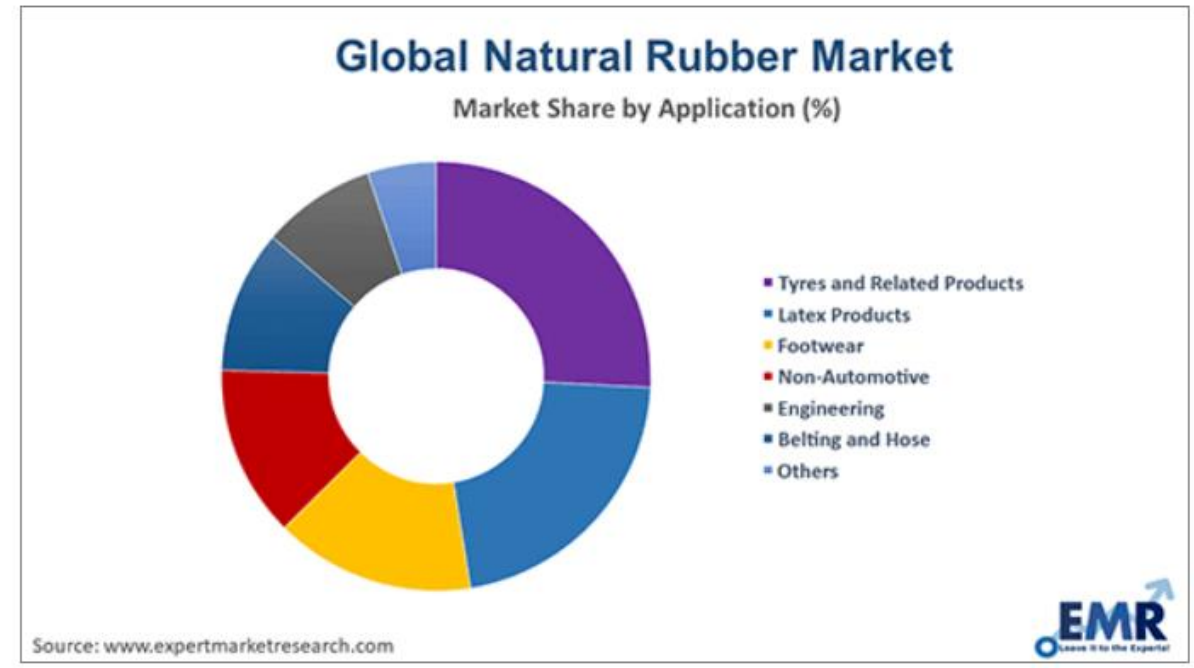

Figure 5: Global Natural Rubber Market share in different sectors [6].

\section{Tires}

One of the main products produced from both synthetic rubber and natural rubber is tires [4]. To produce tires from synthetic rubber, manufacturers starting with mixing liquid latex with acids, which make the material solid. Manufacturers around the world have different processes to produce tires, and each manufacturer has specifications for producing the best quality of tire.

\section{Conclusion}

The Natural rubber from plants and synthetic rubber from Butadiene are highly competitive, substitutable, and play a major role in the petrochemical industry. The importance of technology implementation can be 
Abdulaziz K Bubshait, Int. Ann. Sci.; Vol. 11, Issue 1, pp: 22-26, 2021

shown by looking into the butadiene rubber growth and market. The butadiene rubber is growing since the synthetic rubber can be produced from Oil. However, the natural rubber has limitation in production rate because of the nature of production processes. The demand in rubber application has been increased and forecasted to reach $\$ 23.2$ billion in five years. Many companies around the world are expanding in the butadiene plants and increasing the production rate to meet the global demand. The variety of applications related to Butadiene rubber assisted the market to have new kind of materials that support deferent markets around the world. The business movements indicated the ability to increases the global market and capacities in the synthetic rubber market, which will enhance the chemical process techniques, new technology design, and efficiency that will maximize production and minimize product cost. The new technologies enhanced materials selection to achieve the accurate yields and product specification. All technologies providers competing in the market provides the minimum OPEX for the plant design. The enhancement deliver is to maximum efficiency, stability and reliability. In additional, to produce different kind of materials and to be able to replace old and heavy materials with more reliable and lighter and strength. To conclude, butadiene rubber material in the petrochemical industry and particularly to the C4 olefins family are growing rapidly and has many useful industrial applications which is recommended to invest on in the future. Finally, it is clear that the demand of Butadiene rubber around the world are increasing since the demand of the rubber applications are increasing as well. Also, the world population are rises which will grow the demand in different product applications.

\section{Competing Interests}

The authors whose names are in the paper below certify that they have NO affiliations with or involvement in any organization or entity with any financial interest (such as honoraria; educational grants; participation in speakers' bureaus; membership, employment, consultancies, stock ownership, or other equity interest; and expert testimony or patent-licensing arrangements), or non-financial interest (such as personal or professional relationships, affiliations, knowledge or beliefs) in the subject matter or materials discussed in this manuscript.

\section{How to Cite this Article:}

A. K. Bubshait, "Butadiene Rubber in the Petrochemical Industry", Int. Ann. Sci., vol. 11, no. 1, pp. 22-26, Dec. 2021. https://doi.org/10.21467/ias.11.1.22-26

\section{References}

[1] W. NEL, "Chemical profile: Europe Butadiene," ICIS News. https://www.icis.com/subscriber/icb/chemicalprofile?commodityId=10204\&regionId=10345 (accessed Dec. 31, 2021).

[2] "Expert Market Research: Industry Reports | Analysis | Consultant.” https://www.expertmarketresearch.com/ (accessed Dec. 31, 2021).

[3] "Synthetic Rubber Market Global Forecast to 2026 | MarketsandMarkets." https://www.marketsandmarkets.com/MarketReports/synthetic-rubber-market-761.html (accessed Dec. 31, 2021).

[4] "Plastics \& Rubber.” https://plastics-rubber.basf.com/emea/en.html (accessed Dec. 31, 2021).

[5] H. Matthew, Natural Rubber Vs Synthetic Rubber - The price relationship and demand switchability. https://www.halcyonagri.com/en/natural-rubber-vs-synthetic-rubber-the-price-relationship-and-demand-switchability/ (accessed Dec. 31, 2021).

[6] "Global Natural Rubber Market Report and Forecast 2022-2027." https://www.expertmarketresearch.com/reports/natural-rubbermarket (accessed Dec. 31, 2021).

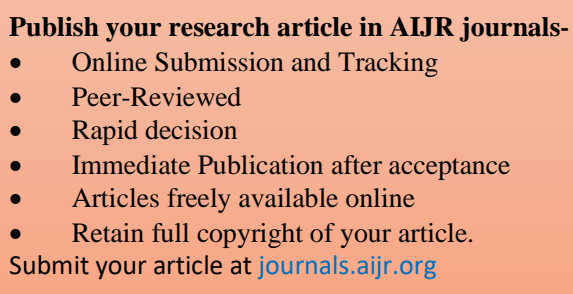

Publish your books with AIJR publisher-

- Publish with ISBN and DOI.

- Publish Thesis/Dissertation as Monograph

- Publish Book Monograph.

- Publish Edited Volume/ Book.

- Publish Conference Proceedings

- Retain full copyright of your books. Submit your manuscript at books.aijr.org 